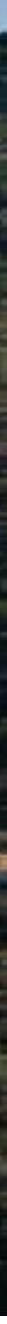

Paisaje de la carretera que discurre entre Vélez-Málaga y Arenas. Foło: Juan Carlos Cazalla, IAPH 


\section{La Axarquía, un paisaje en proceso de transformación}

Manuel Benabent F. de Córdoba, geógrafo-urbanista
La Axarquia o tierra del Este, como la denominaban los árabes, en oposición a la Hoya de Málaga, es un territorio de antigua colonización. Fenicios, romanos y árabes, por no remontarnos a la presencia humana desde el Paleolítico, se han establecido y han ocupado en mayor o menor medida su territorio, y han dejado las huellas del modo en que lo usaban y aprovechaban.

Es por ello que La Axarquia ha sido un territorio fuertemente antropizado y sujeto a grandes transformaciones para adaptarlo a las necesidades de sus diferentes ocupantes. Si fenicios y romanos estaban interesados en su litoral, en establecer colonias desde las que desarrollar una actividad comercial, o para el dominio militar del Mediterráneo y, por añadidura, extraer los recursos, los árabes tendrán una pretensión diferente, una vez asegurada la conquista su intención será permanecer, hacer de esta tierra su lugar de vida, al igual que harán los moriscos, desplazados de otras tierras, siempre acosados y finalmente expulsados y reemplazados por nuevos colonizadores.

De estas sucesivas ocupaciones, especialmente del período musulmán, ha quedado su impronta en el territorio. Su legado más visible ha sido su sistema de asentamientos, no sólo por sus características, por la tipología abigarrada y compacta de sus núcleos de población, sino también por su extraordinaria densidad, que ya el primer nomenclátor de población de la estadistica moderna presentaba en 1860 a La Axarquia como el sistema de poblamiento con mayor número de núcleos y más diseminados de Andalucia. También la disposición de este sistema de asentamientos en el territorio, su extraordinaria red de caminos y los artefactos que dan cuenta de las actividades de las que vivian nos muestran un modelo de ocupación extraordinariamente adaptado para explotar los recursos en un medio anfractuoso, dificil, muy movido, de elevadas pendientes, lomas y valles.

Comarca montañosa, fragmentada, de difícil domesticación, ha mantenido en lo esencial prácticamente invariable su modelo de ocupación y uso del territorio y tras la crisis de la filoxera de finales del XIX que acabó con su pujante actividad económica basada en el viñedo, ha permanecido hasta el último tercio del pasado siglo como un espacio olvidado y anclado en el tiempo, y mientras que buena parte de sus habitantes, ensimismados en sus dificultosas labores agrícolas, basadas en un policultivo de subsistencia que vino en buena parte a sustituir al viñedo, envejecian en torno a una actividad agrícola y ganadera secular, los más jóvenes abandonaban su tierra para buscar mejores horizontes.

La fragilidad del medio físico de La Axarquía, un medio natural limitado y marginal en términos productivos y proclive a la erosión, a lo que se le une la difícil mecanización del campo, el envejecimiento de la población rural y el predominio del minifundismo, son factores explicativos del declive del modelo agrario tradicional. Sólo el desarrollo de la actividad vacacional y en menor medida turística que tuvo lugar en su litoral a partir de los años setenta del pasado siglo, las transformaciones en regadio del valle del Guaro propiciadas por la construcción de la presa de La Viñuela a finales de los ochenta y la más reciente ocupación del interior de la comarca por nuevos habitantes, que tienen en el clima su principal atracción, pusieron freno a su paulatino abandono.

En este proceso La Axarquia se transforma, se detiene la sangría poblacional y aparecen nuevas actividades vinculadas al sector servicios, a la vez que se abandona la actividad agraria secular, en precario en buena parte de este territorio, y los cultivos tradicionales de secano se reducen de acuerdo con los avatares de la Política Agrícola Común y las demandas del mercado a favor del regadio y de los cultivos forzados. Mientras tanto, la caña de azúcar desaparece en su litoral, el aguacate y los citricos se adueñan de las vegas y se elevan mediante desmontes y aterrazamientos por las vertientes, en tanto que los frutales ganan posiciones frente al olivar. De esta manera, el viñedo y el almendro, cultivos básicos de la economía rural, terminan por ser marginales, lo que ha supuesto el abandono de toda una infraestructura de paratas y balates cuidadosa y minuciosamente construidos a lo largo de generaciones para poder cultivar en estas laderas imposibles. 

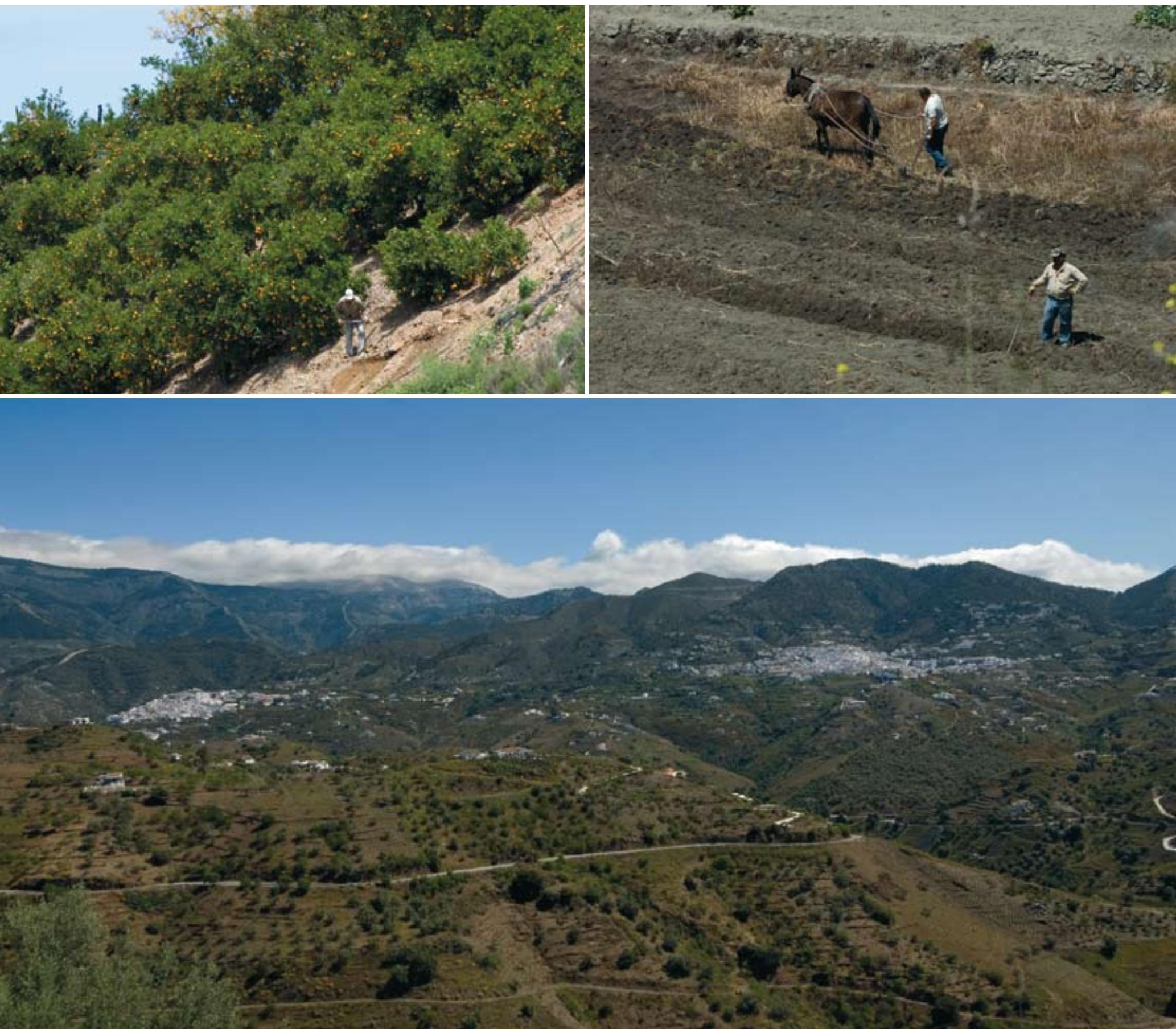

Arriba. Naranjales entre Riogordo y Comares (izquierda). Trabajos agrícolas de preparación de la huerta en la localidad de Sedella (derecha). Abajo. Paisaje que se domina desde Corumbela. Fotos: Juan Carlos Cazalla, IAPH

Las transformaciones agrícolas están teniendo una consecuencia evidente en el capital territorial de La Axarquia, en su patrimonio cultural, natural y paisajistico, en la pérdida de sus valores constitutivos y en su identidad cultural y modelado territorial, perceptibles tanto en las caracteristicas del modo de ocupación del territorio y laboreo agrícola, en los procedimientos empleados para el control de la erosión, en la propia arquitectura popular, como en las técnicas productivas empleadas.

Las consecuencias de la rápida extensión y homogeneización de los nuevos desarrollos agrícolas, con prácticas ajenas a las caracteristicas del propio territorio adecuándolo sin excesiva consideración de sus condiciones, está suponiendo no sólo la banalización del paisaje sino el abandono de prácticas culturales y con ello de las estructuras fisicas y rasgos identificadores de una actividad de siglos adaptada al medio y, por tanto, respetuosa con él.

Esta transformación territorial derivada de la agricultura se ha visto acompañada por el desarrollo urbanistico tanto en el litoral como en el interior, consecuencia del atractivo que supone este territorio y de una demanda que antes de la crisis económica en que nos encontramos estaba sustentada en la disponibilidad de suelo en buena posición respecto al borde litoral a un coste relativo inferior en relación con otras zonas costeras.

El paisaje, junto con el clima, constituye el elemento esencial de la atracción residencial y turistica que experimenta La Axarquía, pero es precisamente la belleza de este paisaje el factor principal 

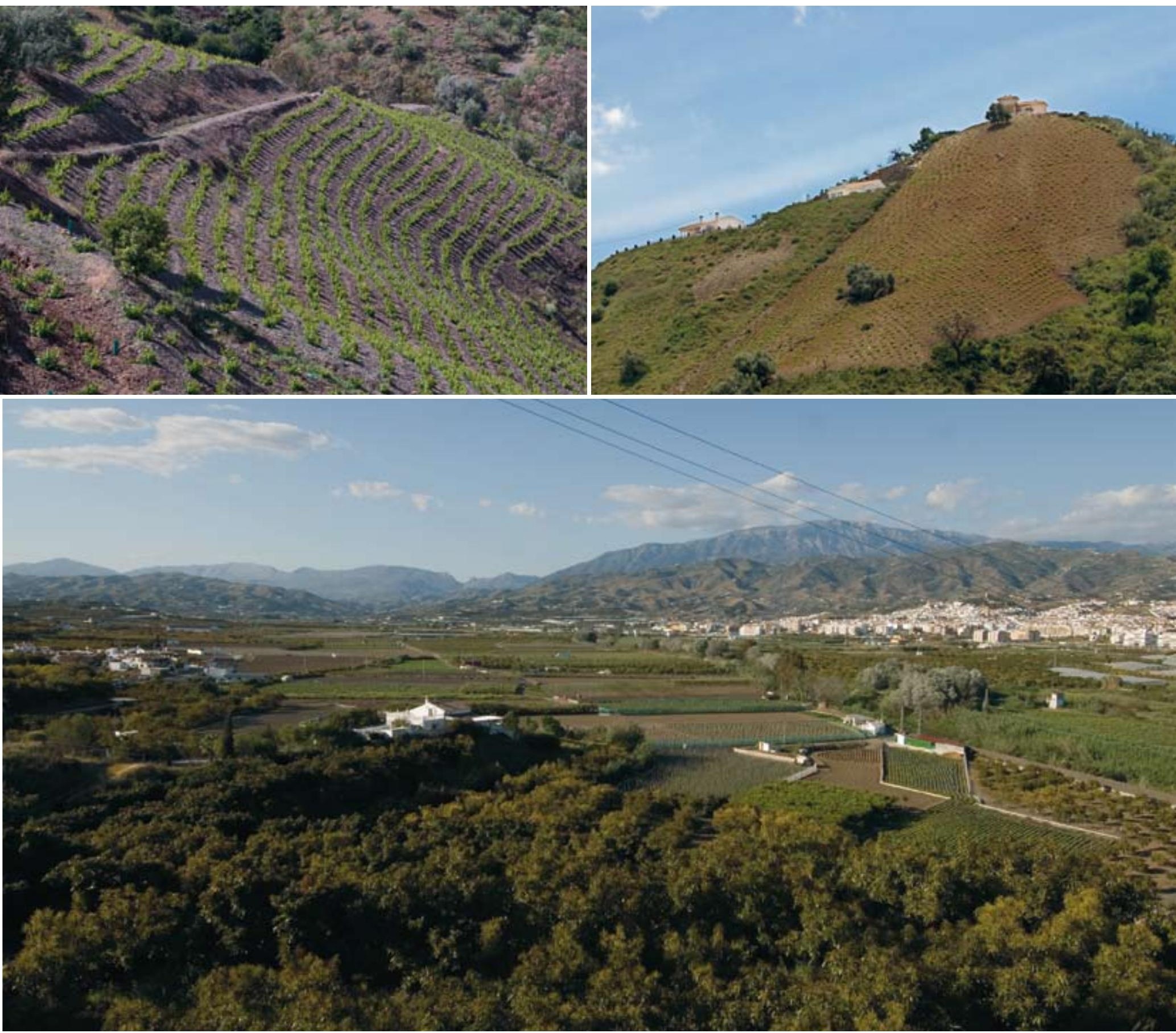

Arriba. Cultivo de vides con el sistema de paratas en Benamargosa (izquierda). Paisaje de viñedos entre Riogordo y Comares (derecha). Abajo. Paisaje que se domina desde Corumbela. Fotos: Juan Carlos Cazalla, IAPH

de su deterioro. Las amplias panorámicas, las distancias medias y largas que ofrecen los montes de tonos marrones oscuros y ocres, festoneados por los grises de las sierras calizas, impiden reconocer o más bien hacen que no pongamos atención a las vistas que ofrecen las distancias de los planos cortos y medios: las intrusiones en el paisaje que rompen tipologías tradicionales; los desmontes que desconocen los procesos erosivos y la sabiduría que encierran las paratas; la pérdida de funcionalidad de los paseros, hoy prácticamente desparecidos; los caminos de acceso a las nuevas viviendas, en pendientes imposibles que se deterioran con las primeras Iluvias; los banales muros de escolleras que sustituyen a los trabajados muros de piedras o encachados; la multiplicación de tendidos eléctricos, conducciones de abastecimiento, etc., que transmiten una sensación de ocupación caótica del territorio, de salpicado que toca todos los espacios, que se desarrolla en todas las cotas y que, en suma, suponen una reescritura del paisaje, que transforma y modifica su esencia misma de forma irreversible.

La capacidad técnica actual para transformar cualquier espacio mediante desmontes y terraplenes para ubicar las edificaciones y sus accesos y para conducir los recursos energéticos e hídricos alli donde se requieran; la posibilidad de alcanzar con los vehículos apropiados todos los lugares; el propio control de los procesos de ocupación del territorio por agentes externos, que desconocen o ignoran los emplazamientos sabiamente seleccionados de los asentamientos tradicionales, las tipologías edificatorias $y$, en suma, la cultura territorial adaptativa a la topografía y a las propias características del sustrato litológico, están dando 


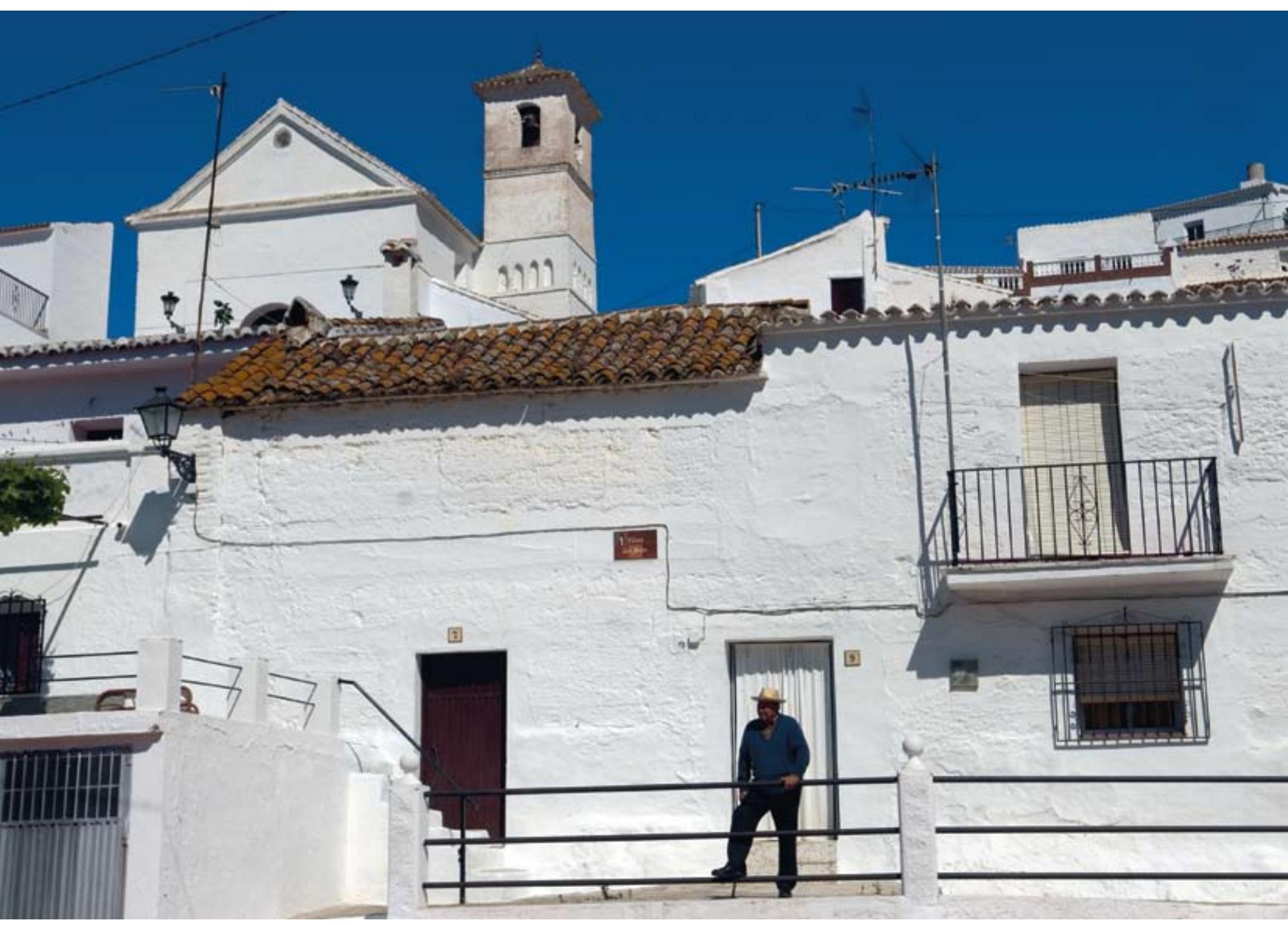

Arquitectura típica de la comarca en Daimalos. Foto: Juan Carlos Cazalla, IAPH

Las intrusiones en el paisaje, como la multiplicación de los tendidos eléctricos, suponen una transformación que modifica su esencia de forma irreversible

lugar a una rapidísima modificación del paisaje. Un paisaje que es el legado de una cultura tradicional adaptada a una orografía complicada y a unos recursos naturales limitados que, encontrando secularmente las condiciones y los medios materiales de su existencia, ha transmitido una diversa gama de contenidos formales o simbólicos y de valores culturales y estéticos propios de un ajuste equilibrado entre usos, capacidades del medio y respuestas del territorio.

Este paisaje de La Axarquía no se corresponde con el estereotipo del paisaje bello que siempre se asocia con espacios poco intervenidos y con recursos naturales bien conservados, sino que se relaciona con un territorio muy humanizado, construido palmo a palmo, y mantenido mediante una ingente labor humana de siglos siguiendo directrices de sostenibilidad y de aprovechamiento al límite de las capacidades instrumentales disponibles en cada época, lo que permite entender el modo de manejo tradicional de este territorio como una economía de uso estrechamente vinculada con su entorno, lo que ha llevado a garantizar su preservación.

La cultura tradicional popular se encuentra hoy en una critica encrucijada en la que confluyen multitud de factores y sinergias de dificil salida, entre los que destacan: el declive de estas comunidades rurales $y$, en paralelo, el abandono imparable de los espacios productivos tradicionales y la aparición de extensos territorios con apariencia de baldíos; un fuerte choque de costumbres entre lo autóctono y la modernidad, representado por actuaciones que no se adaptan a las características del paisaje, insensibles ante el incalculable legado cultural; la irracionalidad e insostenibilidad de ciertos sectores de la nueva economía agraria dirigida por premisas de viabilidad y rentabilidad a corto plazo; o la falta de atención a unos sistemas naturales (suelos, drenajes, etc.) debilitados y descontrolados, que con el tiempo se van perfilando como factores de riesgo para los propios sistemas productivos de La Axarquía. 


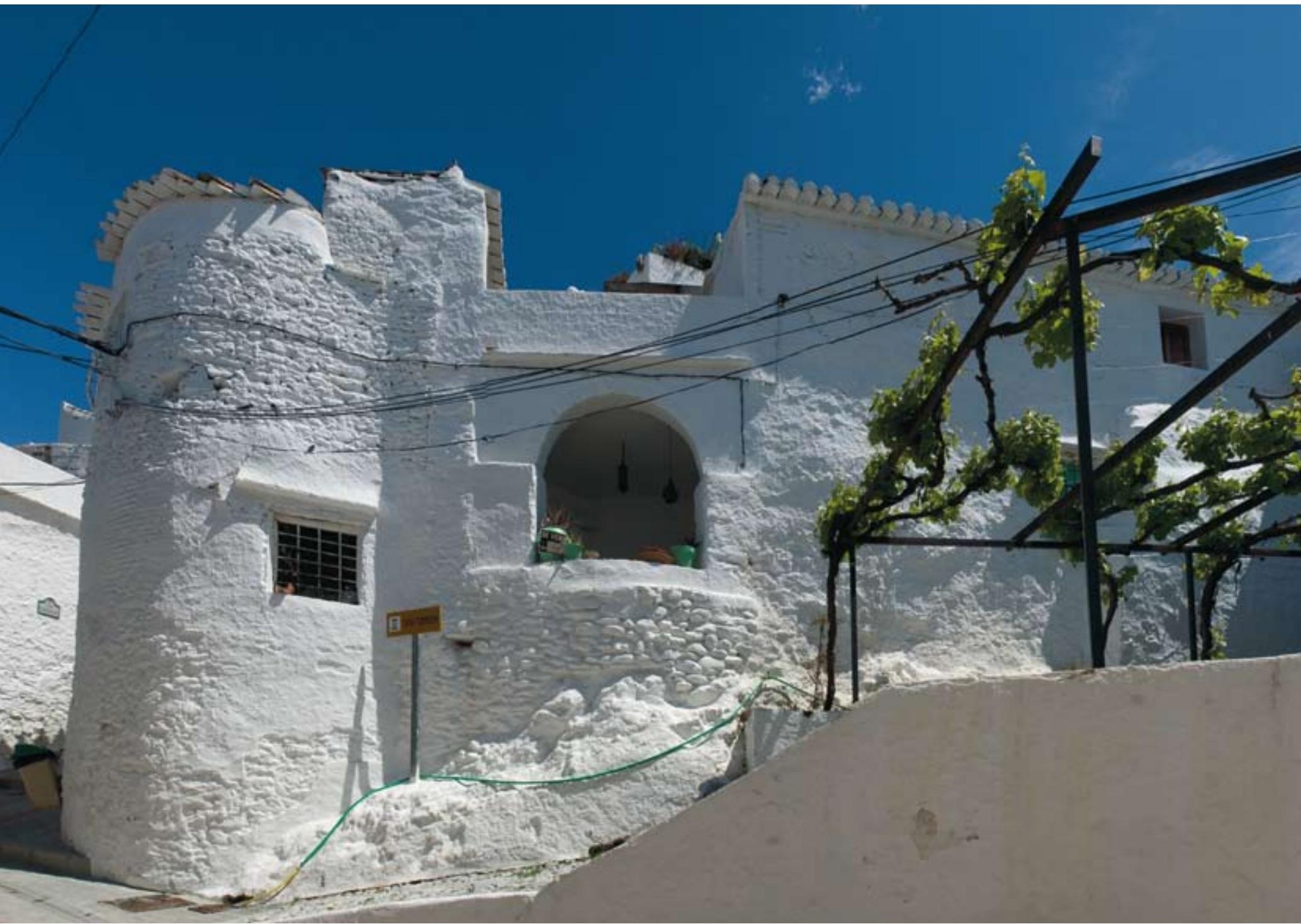

Torreón de Salares. Foto: Juan Carlos Cazalla, IAPH

En esta situación de incertidumbre y de choque cultural se está registrando un proceso de banalización y aculturación, identificable en términos de pérdida neta de valores culturales y estéticos y de sostenibilidad agrícola, y se está produciendo, bajo la forma de la residencia vacacional rural, la aparición de una nueva identidad paisajística y territorial confeccionada por un modelo de desarrollo rural regulado por la insensibilidad cultural y ambiental y por la especulación como factor de competitividad y uso del territorio.

Así, el paisaje de La Axarquía se encuentra en un momento de confluencia entre dos modelos de entenderlo: el tradicional, confeccionado por la cultura en decadencia, y el traido por la modernidad, con una importante inercia expansionista, muchas de las veces ambientalmente insostenible e insensible ante el patrimonio del entorno. El primero ha creado paisaje y generado el recurso, el segundo reconoce estas apreciables cualidades, aporta escasos valores y opera en términos de degradación y desestabilización generalizada bajo un común denominador, que estriba en la adaptación de los terrenos, cimas y laderas, a las exigencias de su actividad.
El resultado es la complejidad y dureza de las obras ejecutadas y el descuido u olvido de las inserciones paisajisticas. Fragilidad de los paisajes, abandono de la gestión por parte de sus pobladores, e intervenciones intensas y poco adaptadas a las características del medio, entre otros, son aspectos claves en la concepción de esta nueva situación en la que los criterios de productividad y competitividad se imponen sobre unos aprovechamientos de un medio natural limitado y marginal en términos productivos, así como sobre las valoraciones sociales y culturales hasta hace bien poco existentes. Hoy, el declive de la sociedad rural y el abandono del espacio agrícola tradicional dan lugar a un proceso imparable de pérdida de identidad y de valores paisajísticos y culturales, así como de homogeneización de medios, ambientes rurales y paisajes comarcales.

La toma de conciencia de esta situación por sus habitantes, la crisis económica que ha aflojado la tensión urbanistica sobre La Axarquia y el paulatino gobierno del territorio mediante la adopción de instrumentos de planificación territorial y urbanisticos suponen la esperanza de un cambio de rumbo que adecue el desarrollo necesario con la recuperación de su capital territorial. En La Axarquía ambas cuestiones están unidas. 

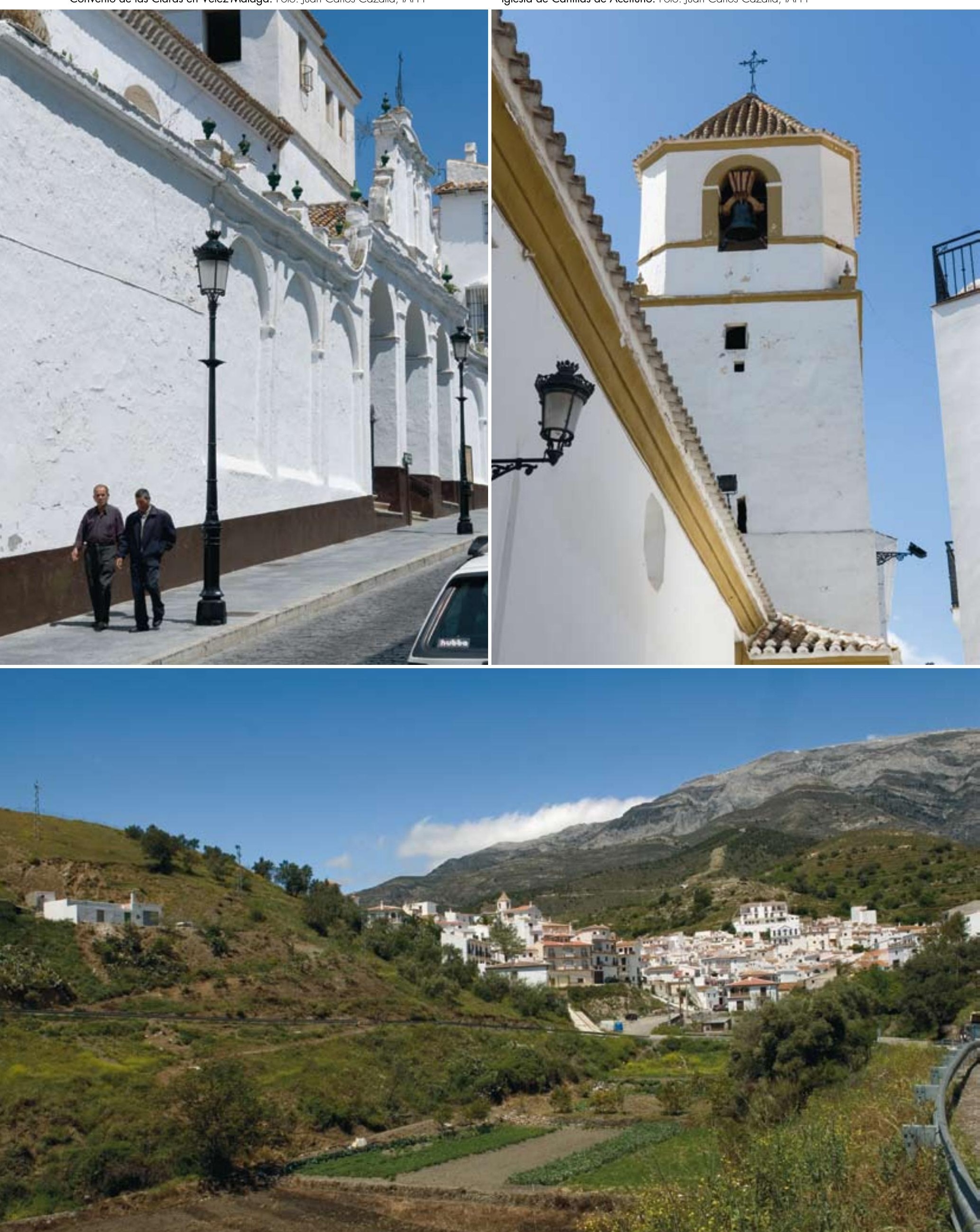


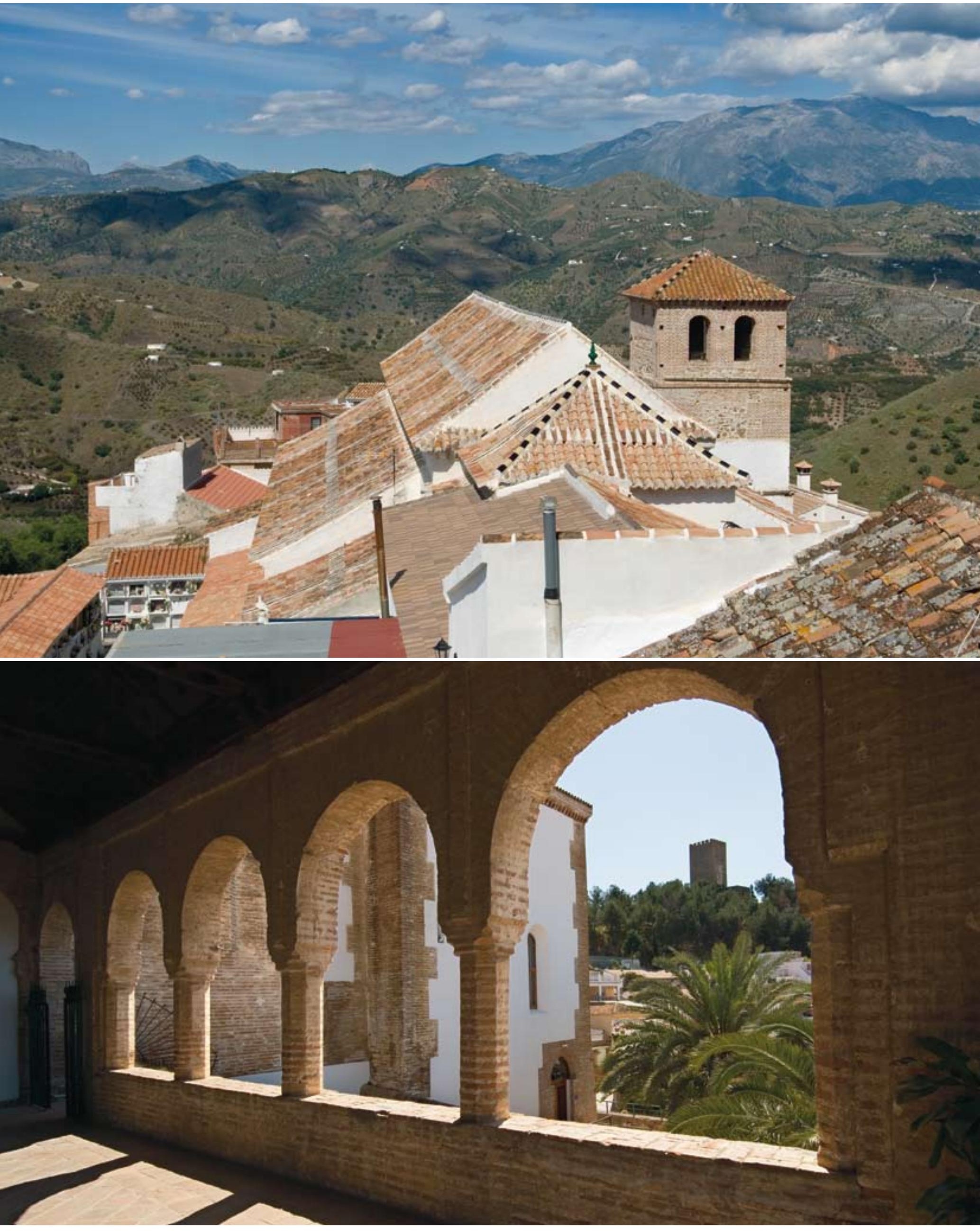

Iglesia de Santa María en Vélez-Málaga. Foto: Juan Carlos Cazalla, IAPH 